\title{
Change in Sensory Functioning Predicts Change in Cognitive Functioning: Results from a 6-Year Follow- Up in the Maastricht Aging Study
}

Citation for published version (APA):

Valentijn, S. A. M., van Boxtel, M. P. J., van Hooren, S. A. H., Bosma, J. H. A., Beckers, H. J. M., Ponds, R. W. H. M., \& Jolles, J. (2005). Change in Sensory Functioning Predicts Change in Cognitive Functioning: Results from a 6-Year Follow-Up in the Maastricht Aging Study. Journal of the American Geriatrics Society, 53, 374-380. https://doi.org/10.1111/j.1532-5415.2005.53152.x

Document status and date:

Published: 01/01/2005

DOI:

10.1111/j.1532-5415.2005.53152.x

Document Version:

Publisher's PDF, also known as Version of record

Please check the document version of this publication:

- A submitted manuscript is the version of the article upon submission and before peer-review. There can be important differences between the submitted version and the official published version of record.

People interested in the research are advised to contact the author for the final version of the publication, or visit the DOI to the publisher's website.

- The final author version and the galley proof are versions of the publication after peer review.

- The final published version features the final layout of the paper including the volume, issue and page numbers.

Link to publication

\footnotetext{
General rights rights.

- You may freely distribute the URL identifying the publication in the public portal. please follow below link for the End User Agreement:

www.umlib.nl/taverne-license

Take down policy

If you believe that this document breaches copyright please contact us at:

repository@maastrichtuniversity.nl

providing details and we will investigate your claim.
}

Copyright and moral rights for the publications made accessible in the public portal are retained by the authors and/or other copyright owners and it is a condition of accessing publications that users recognise and abide by the legal requirements associated with these

- Users may download and print one copy of any publication from the public portal for the purpose of private study or research.

- You may not further distribute the material or use it for any profit-making activity or commercial gain

If the publication is distributed under the terms of Article $25 \mathrm{fa}$ of the Dutch Copyright Act, indicated by the "Taverne" license above, 


\title{
Change in Sensory Functioning Predicts Change in Cognitive Functioning: Results from a 6-Year Follow-Up in the Maastricht Aging Study
}

\author{
Susanne A. M. Valentijn, MSc, ${ }^{*}$ Martin P. J. van Boxtel, MD, ${ }^{*}$ Susan A. H. van Hooren, MSc, ${ }^{*}$ \\ Hans Bosma, PhD, ${ }^{\dagger}$ Henny J. M. Beckers, MD, ${ }^{\ddagger}$ Rudolf W. H. M. Ponds, PhD, ${ }^{*}$ and Jelle Jolles, PhD*
}

OBJECTIVES: To examine the longitudinal relationship between sensory functioning and a broad range of cognitive functions after 6 years follow-up and whether cataract surgery or first-time hearing aid use affected cognition.

DESIGN: Hierarchical regression procedures were employed to determine whether sensory functioning was predictive of cognitive performance.

SETTING: Maastricht University and the University Hospital Maastricht, the Netherlands.

PARTICIPANTS: Older Dutch adults $(\geq 55)$ enrolled in the Maastricht Aging Study $(\mathrm{N}=418)$.

MEASUREMENTS: Visual and auditory acuity, the Visual Verbal Learning Test (VVLT), the Stroop Color Word Test (SCWT), the Concept Shifting Task (CST), the Verbal Fluency Test, and the Letter-Digit Substitution Test (LDST).

RESULTS: A change in visual acuity was associated with change in most cognitive measures, including the total and recall scores of the VVLT, the mean score of the first two SCWT cards, the mean score of the first two CST cards and the LDST. In addition, a change in auditory acuity predicted change in memory performance (VVLT total and recall scores), and auditory acuity measured at baseline predicted change in the mean score of the first two SCWT cards and the LDST.

CONCLUSION: The findings support the notion of a strong connection between sensory acuity in auditory and visual domains and cognitive performance measures, both from a cross-sectional and a longitudinal perspective. They also suggest that it is essential to screen older individuals in a clinical context for sensory functioning so that changes in visual or auditory acuity are not interpreted as changes in

From the * Department of Psychiatry and Neuropsychology, European Graduate School of Neuroscience and ${ }^{\dagger}$ Care and Public Health Research Institute, Department of Health Care Studies, Maastricht University, the Netherlands; and ${ }^{\ddagger}$ Department of Ophthalmology, University Hospital Maastricht, Maastricht, the Netherlands.

A grant from the Dutch Research Council funded this study (NWO: 014-91-047) as part of the "Successful Aging" program.

Address correspondence to S. A. M. Valentijn, Department of Psychiatry and Neuropsychology, Maastricht University, PO Box 616, 6200 MD Maastricht, the Netherlands. E-mail: S.Valentijn@np.unimaas.nl cognitive performance. J Am Geriatr Soc 53:374-380, 2005.

Key words: vision; hearing; cognition; aging; longitudinal study

$V_{1}$ isual and hearing impairments are common in old age. It has been suggested that at least $50 \%$ of individuals aged 75 and older show some degree of measurable hearing loss, and that best-corrected visual acuity starts to decline after age $45 .{ }^{1}$ Sensory impairment can dramatically affect the ability to socialize and psychological or emotional functioning, functional status, and thus quality of life. ${ }^{2-7}$ Moreover, in the literature on cognitive aging, a strong connection has been found in cross-sectional studies between sensory functioning and cognition. ${ }^{8-12}$ The purpose of this study was to examine the longitudinal covariation of sensory function and cognitive functioning, independent of age, sex, and education.

The nature of this association is still ambiguous, and several alternative explanatory hypotheses have been proposed. Although this study was not designed to test these different hypotheses, it is interesting to discuss the mechanisms that have been suggested. Currently, four hypotheses specify different mechanisms that indicate a link between sensory functioning and cognition. Two hypotheses hold that there is a direct causal association between sensory impairment and cognitive functioning. The "sensory deprivation" hypothesis states that a prolonged lack of adequate sensory input will result in cognitive deterioration due to neuronal atrophy. ${ }^{9,13}$ The second hypothesis states that sensory-impaired individuals have to allocate more attentional resources to perceive and interpret sensory information. As a result, according to this "resource allocation" hypothesis, there may be fewer resources left for other cognitively demanding tasks. ${ }^{14}$ The third hypothesis, the "common cause" hypothesis, postulates that a third common factor confounds the association between sensory functioning and cognition. Sensory impairment and cognitive 
decline may both be the result of age-related changes in a shared factor, such as degeneration of central nervous structures. ${ }^{8,9,15}$ An alternative fourth hypothesis is that sensory-impaired individuals are disadvantaged in their performance on psychometric tests as a direct result of difficulties in sensory perception. According to this notion, impaired performance on cognitive tasks is not a result of cognitive ability per se but a direct consequence of unclear and distorted perceptual information delivered to the cognitive system, thereby compromising performance on neuropsychological tests. ${ }^{10,11,16,17}$ Cognitive functioning is an important prerequisite for successful aging and independent living. Therefore, it is essential to identify variables associated with cognition that may predict future cognitive performance and may be amenable to treatment. Few longitudinal studies have investigated the predictive value of sensory impairment on subsequent cognitive functioning. ${ }^{18}$ For example, one ${ }^{19}$ found that diminished visual acuity was associated with decline in memory functioning but not with performance on other cognitive domains. In contrast, no association was found between diminished auditory functioning and decline in any of the cognitive domains. This dissociation between vision and hearing in relation to cognition has been used as an argument against a commoncause explanation used in several cross-sectional studies, because a fourth common factor apparently did not affect vision, hearing, and cognition at the same time. ${ }^{19}$

Because the sensory deprivation and the resource reallocation theories imply that improvement of sensory functioning could result in improvement of cognition, in the present longitudinal study, not only the relationship between sensory functioning and a broad range of cognitive functions after a 6-year follow-up, but also whether selfinitiated treatments, such as cataract surgery or the use of a hearing aid would affect cognition, were investigated. Data obtained from relatively healthy older Dutch adults collected in the Maastricht Aging Study (MAAS), a longitudinal study of normal aging, were used. ${ }^{20,21}$

\section{METHODS}

\section{Participants}

All participants were recruited from the MAAS, a longitudinal study of the determinants and consequences of pathological and successful aging and of cognitive functioning in particular. In the MAAS, a range of experimental and standardized instruments of health and psychological functioning were used to collect data at baseline and at two follow-up occasions, each separated by 3 years. Participants were selected from a register of 15 family practices in the south of the Netherlands, ${ }^{22}$ were aged 24 to 81 , and at the moment of inclusion were without medical conditions known to interfere with normal cognitive functioning (e.g., dementia, mental retardation, and cerebrovascular pathology). Overt visual or auditory handicaps (i.e., inability to read or understand spoken word with relative ease) also lead to baseline exclusion. The study population was stratified by age, sex, and general ability. General ability was defined as the level of occupational achievement of individuals, which incorporates the degree of complexity of professional work and the knowledge and experience required. ${ }^{20}$
All participants gave informed consent. More study details can be found elsewhere. ${ }^{20,21,23}$ The current study used the data for a smaller sample of 418 individuals (214 men; 204 women) aged 55 and older at baseline, with a mean age \pm standard deviation of $65.9 \pm 6.7$ (range 5583 ). Of this group, 27 received an intervention to improve vision (cataract surgery) or hearing (hearing aid use) during the 6 years of follow-up and were analyzed separately. Mean level of education was $3.0 \pm 1.8$ measured on a hierarchical scale of schooling available in the Dutch educational system (comparable to 10 years of formal education). Level of education (1-8) was scored as follows: $1=$ primary education, 2 = lower vocational education, $3=$ intermediate general secondary education, $4=$ intermediate vocational education, $5=$ higher general secondary education/ university preparatory education, $6=$ higher vocational preparatory education, $7=$ higher professional education, $8=$ university education. ${ }^{24}$ Participants rated themselves as healthy (mean $3.69 \pm 0.64$ on a $1-5$ rating of perceived health, $1=$ very poor health to $5=$ very good health) and had no serious cognitive problems (mean Mini-Mental State Examination score of $27.8 \pm 1.82) .{ }^{25}$ In addition, a clinical interview was used to exclude individuals suffering from dementia from further participation.

\section{Measures \\ Cognitive Measures}

The Visual Verbal Learning Test (VVLT) ${ }^{26}$ is a verbal memory task designed to measure the ability to learn new verbal information and to retrieve this information from memory. Fifteen low-associative words are visually presented in a booklet five times. The font size of the letters is large enough for all participants to perceive the words well. After each presentation, the participant is asked to recall as many words as possible, with no restriction on the order of recall (immediate recall). The five trials provide a reliable estimate of learning, and scores for each trial are summed to produce a total VVLT score. The maximum score after five successive trials is 75 . Twenty minutes after the last presentation, participants are again requested to recall as many correct words as possible (VVLTr).

The Stroop Color Word Test (SCWT) is used as a measure of selective attention and speed of information processing and consists of three cards..$^{27,28}$ On the first card, color words (red, blue, yellow, and green) are printed in black ink, and participants are asked to read the words as fast and accurately as possible. The second card displays color patches in the same four colors, and participants are asked to name the colors of the patches as fast and accurately as possible. The third card displays color words that are printed in incongruously colored ink, and participants are asked to name the color of the ink in which the words are printed. The variables of interest in this study are the mean scores of the total time needed to complete the first two cards as an indication of simple speed capacity (SCWT $1+2)$ and an interference score to measure inhibition of a habitual response (reading the word) (SCWT i). This latter interference score is computed by subtracting the mean score of the first and second cards from the time needed to complete the third card. 
The Concept Shifting Task (CST) is a modified version of the Trail Making Test and is used as an instrument to measure simple speed and cognitive flexibility. ${ }^{29,30}$ The test consists of three cards containing the stimulus material, which are 16 small circles grouped in a large circle. On the first card, the smaller circles contain numbers in a fixed random order, and participants are asked to cross out the numbers in the right order, as fast and accurately as possible. In the second part of the test, the circles contain letters, which have to be crossed out in alphabetical order. In the third part of the test, the card displays numbers and letters, and participants are requested to alternate between numbers and letters. The scores correspond to the time needed to complete each card. The mean scores of the first two cards are used as a reflection of simple speed (CST $A+B)$. The difference between the score for the third card and the mean score of the first two cards is considered to reflect the additional time needed to shift between two sets of stimuli (CST i).

The Verbal Fluency Test (VFT) is a subtask of the Groninger Intelligence Test ${ }^{31,32}$ and measures the ability to recollect as many words as possible in a specific category (animals) from memory in an adequate and strategic manner. The outcome measure of interest is the total number of words produced in 90 seconds.

The Letter-Digit Substitution Test (LDST) is a modified version of the Symbol Digit Modalities Test and measures general information processing speed. ${ }^{32,33}$ Participants are asked to fill in as many blank squares as possible using a code supplied at the top of the page. In this code, nine random letters of the alphabet correspond to nine different numbers. Participants have to copy the correct number in each box, indexed by a letter. The dependent variable is the total number of correctly filled in squares in 90 seconds.

\section{Sensory measures}

Best-corrected visual acuity was measured for both eyes using a Landolt-C optotype chart at a distance of 5 meters under standard luminescence and with corrected vision. ${ }^{34}$ Participants are requested to say in which direction the opening of black circles on a white background points (up, down, left, right). The outcome measure is the size of the last circle whose opening was correctly identified and is expressed as the ratio of 5 meters to the distance at which a reference group is able to encode the circle orientation (e.g., 1 is average for young individuals with normal visual acuity). Higher scores indicate better visual acuity.

Hearing acuity is expressed in $\mathrm{dB}$ and was measured with pure-tone auditory thresholds that were determined for both ears at different fixed frequencies at 1, 2, and 4 $\mathrm{KHz}$ using a screening audiometer (Interacoustics AS7, Denmark). The overall hearing acuity, expressed as the average of the hearing thresholds for the better ear, was measured according to recommendations for the assessment of hearing handicap. ${ }^{35}$ Higher scores indicate worse auditory acuity.

\section{Procedure}

The outcome variables were obtained from a neuropsychological test battery that included the VVLT, the SCWT, the CST, the VFT, and the LDST. On average, completion of a test session took 2.5 hours, with a rest period of 20 minutes. All participants were tested at the test laboratory of the University Hospital Maastricht. Trained assistants supervised by neuropsychologists and physicians of the project staff administered cognitive and sensory measures, and comparable test protocols were used on all three measurement occasions.

\section{Statistical analysis}

For the cross-sectional data, zero-order correlations were computed between age, education, sex, and sensory and cognitive variables measured at baseline. Next, hierarchical linear regression analysis was employed to examine the relationship between baseline sensory functioning and baseline cognitive functioning.

Hierarchical linear regression analysis was used also to examine the association between sensory functioning and change in cognitive performance after 6 years. In this regression analysis, three blocks of predictors were constructed; age, sex, and education were entered first; followed by baseline cognitive performance at the second step; and change in vision or hearing and baseline vision or hearing at the third step.

With respect to the longitudinal analyses, a change in vision or hearing was computed as the regression coefficient $\mathrm{B}$ (slope) of the individual regression line that was fitted based on the three available measurements of sensory function (baseline, 3 years follow-up, 6 years follow-up). Baseline vision and hearing scores were expressed as the intercept of this regression line. All statistical analyses were performed using SPSS for Macintosh, version 10 (SPSS Inc., Chicago, IL).

\section{RESULTS}

Descriptive data at baseline and 6 years follow-up for individuals who did not undergo any interventions during the 6 years of follow-up are given in Table 1. At baseline, 240 individuals had reading glasses for far-sightedness ( $\mathrm{n}=231$ ), 189 used eyeglasses to correct near-sightedness $(\mathrm{n}=181), 30$ used one hearing aid, and 14 used hearing aids for both ears (main reason was presbyacusia, $n=23$ ). Male participants had better visual acuity than women at baseline $\left(\mathrm{F}_{1,389}=9.139, P<.01\right)$, at 3-year follow-up $\left(\mathrm{F}_{1,366}=\right.$ 10.327, $P<.01)$, and at 6-year follow-up $\left(\mathrm{F}_{1,366}=8.054\right.$, $P=.01)$. Women had better hearing acuity than men only at the 6-year follow-up measurement $\left(\mathrm{F}_{1,358}=3.990, P=.05\right)$ (results not tabulated).

In addition, results indicated that, at baseline 30 $(7.7 \%)$ of these individuals could be regarded as having auditory impairment because their average pure-tone auditory threshold in the better ear was $35 \mathrm{~dB}$ or more measured at 1,2 , and $4 \mathrm{KHz}^{35}$ At 6-year follow-up, $128(32.7 \%)$ individuals had auditory impairment. At baseline, 36 $(9.2 \%)$ of the participants had a mean visual acuity of 0.5 or less, an often-used clinical cutoff point to determine impaired vision. ${ }^{11}$ Six years later, $42(11.4 \%)$ participants had a mean visual acuity of 0.5 or less.

The zero-order correlations between the sensory variables (visual acuity and auditory acuity), the cognitive variables, and the demographic variables are summarized in Table 2. These scores were highly intercorrelated, with 


\begin{tabular}{|c|c|c|}
\hline Characteristic & Baseline & 6-Year Follow-Up \\
\hline Age, mean $\pm S D$ & $65.1 \pm 6.6$ & \\
\hline Education, mean $\pm \mathrm{SD}$ & $3.1 \pm 1.8$ & \\
\hline Female, \% & 48.6 & \\
\hline Married/living together, \% & 79.5 & \\
\hline \multicolumn{3}{|c|}{ Cognitive measures, mean \pm SD (range) } \\
\hline Mini-Mental State Examination* & $27.9 \pm 1.8$ & $28.1 \pm 1.9$ \\
\hline VVLT total* & $42.6 \pm 9.2(14.0-68.0)$ & $46.0 \pm 10.3(12.0-70.0)$ \\
\hline VVLT recall* & $8.8 \pm 2.8(1.0-15.0)$ & $9.5 \pm 3.3(0.0-15.0)$ \\
\hline SCWT $1+2^{\dagger}$ & $53.2 \pm 8.6(34.5-88.6)$ & $55.3 \pm 9.4(36.9-100.5)$ \\
\hline SCWT interference $^{\dagger}$ & $52.8 \pm 19.9(19.0-148.7)$ & $61.6 \pm 33.6(15.3-281.6)$ \\
\hline $\mathrm{CST} A+\mathrm{B}^{\dagger}$ & $26.8 \pm 6.5(14.8-54.8)$ & $29.4 \pm 8.2(15.2-73.6)$ \\
\hline CST interference $^{\dagger}$ & $14.1 \pm 11.6(-2.0-93.9)$ & $18.9 \pm 16.1(-9.4-148.4)$ \\
\hline Fluency* & $22.4 \pm 5.9(6.0-40.0)$ & $20.9 \pm 5.7(7.0-40.0)$ \\
\hline Letter-Digit Substitution Task ${ }^{\dagger}$ & $42.6 \pm 9.6(17.0-70.0)$ & $43.1 \pm 10.8(13.0-77.0)$ \\
\hline Visual acuity & $1.0 \pm 0.3(0.3-2.0)$ & $1.0 \pm 0.4(0.1-3.0)$ \\
\hline Auditory acuity & $16.0 \pm 11.4(0.0-58.3)$ & $29.2 \pm 14.9(1.7-80.0)$ \\
\hline
\end{tabular}

\footnotetext{
* Higher scores indicate better neuropsychological test performance.

${ }^{\dagger}$ Lower scores indicate better neuropsychological test performance.

$\mathrm{SD}=$ standard deviation; VVLT $=$ Visual Verbal Learning Test; SCWT $=$ Stroop Color Word Test; CST $=$ Concept Shifting Task
}

zero-order correlations ranging from 0.11 to 0.83 (all $P<.05)$.

Based on the cross-sectional data, a hierarchical regression analysis was used to examine whether visual and hearing acuity measured at baseline was predictive of the different cognitive variables. Results indicated that, after controlling for age, educational attainment, and sex, baseline visual acuity was predictive of scores on the SCWT $1+2(\mathrm{~B}=-2.75, t=-1.98, P=.05)$, the CST $\mathrm{A}+\mathrm{B}(\mathrm{B}=-2.49, t=-2.54, P=.01)$, and the LDST $(\mathrm{B}=$ $3.47, t=-2.57, P=.01)$. No associations were found with the remaining cognitive variables.

Auditory acuity was not significantly associated with any of the cognitive variables investigated (not tabulated).

The second set of planned regression analyses was employed to examine whether visual and hearing acuity at baseline and a change in vision and hearing were predictive of change in cognitive performance in 6 years. The results of these analyses revealed that, after controlling for the demographic variables and baseline cognitive performance, change in visual acuity predicted change in the VVLT total score $(\mathrm{B}=5.47, t=2.47, P=.01)$, the VVLTr $(\mathrm{B}=2.04$, $t=2.75, P=.01)$, the SCWT $1+2(\mathrm{~B}=-5.25, t=-3.09$, $P<.01)$, the CST A+B $(\mathrm{B}=-3.63, t=-2.20, P=.03)$, and the LDST $(\mathrm{B}=4.74, t=2.80, P=.01)$. All effects indicated that deterioration of visual acuity was associated with worse cognitive performance. No effects were found for the SCWT $i$ and the CST i scores and for the VFT. Furthermore, baseline visual acuity was not associated with change in cognitive performance.

A 6-year change in auditory acuity predicted change in the total score of the VVLT $(\mathrm{B}=-0.24, t=-2.37$, $P=.02)$ and the VVLTr $(\mathrm{B}=-0.07, t=-2.04, P=.04)$. Baseline auditory acuity was predictive of change in SCWT $1+2(\mathrm{~B}=6.79, t=2.30, P=.02)$ and LDST $(\mathrm{B}=-0.06$, $t=-2.21, P=.03)$ scores. All associations indicated that a decline in auditory acuity or worse hearing at baseline was associated with worse cognitive performance (Table 3).
Additional analyses were done to examine the effect of self-initiated treatments to improve vision or hearing on cognitive performance after 6 years of follow-up. Twentytwo individuals underwent cataract surgery during the MAAS study (mean age $=72.7$, mean visual acuity at baseline $=0.83 \pm 0.26$, and mean visual acuity after 6 years $=0.85 \pm 0.39$ ), and seven people were fitted with a hearing aid (mean age $=69.6$, mean hearing acuity at baseline $=30.95 \pm 9.07$, and mean hearing acuity at 6 years $=56.11 \pm 3.90)$. Hierarchical analyses with a dummy variable (intervention, yes/no) as an additional step did not indicate that the intervention had a significant effect on the different cognitive measures (results not shown).

\section{DISCUSSION}

The objective of this study was to determine whether (changes in) visual and auditory acuity are predictive of change in cognitive performance after a 6-year follow-up. The results indicated that a change in visual acuity was associated with change in most cognitive measures, including the VVLT and the VVLTr, the mean score of the first two SCWT cards, the mean score of the first two CST cards, and the LDST test, but no effects were found on the interference scores of the SCWT and the CST test and on the VFT. Change in auditory acuity was found to be associated with change in memory performance (VVLT and VVLTr scores), and acuity measured at baseline predicted change in the mean score of the first two SCWT cards and the LDST. Although an association between a change in hearing and memory performance was found, the predictive value of a change in visual acuity was more consistent and pronounced. These results confirm earlier longitudinal data derived from the Australian Longitudinal Study of Aging, in which a decline in vision, but not in hearing, was associated with a decline in memory performance after a 2-year follow-up. ${ }^{19}$ In contrast, another study ${ }^{18}$ found that only 
auditory acuity was associated with change in intellectual performance.

With respect to the cross-sectional findings, the results of the present study corroborate earlier findings in that the association between sensory impairment and cognition was shown to be dynamic over a longer period of time. (Change in visual acuity predicted change in cognition after 6 years follow-up.)

To elucidate the relationship between sensory functioning and cognition, several alternative hypotheses are postulated. Although the results of this longitudinal study may help to provide more insight into the nature of the relationship, the current study was not specifically designed to single out the best explanatory model(s). Because this study indicated a robust and consistent relationship between sensory functioning and cognition only for visual acuity, it seems unlikely that an age-related common factor affects both sensory functioning and cognition. However, sensory function was measured peripherally. Because the "common cause" hypothesis refers to sensory impairments that are caused by neuronal deficits that are not easily rehabilitated at the level of the end organ, a "common" factor may still operate on a central level of information processing. Therefore the common cause hypothesis cannot be precluded.

Change in visual acuity was not predictive for performance on all cognitive tests; no association was found with the SCWT and CST interference scores and a VFT score. It is possible that this is because these particular tasks depend on different cognitive domains and are reflections of executive functioning, which may have a different relationship with sensory impairment than other domains, including memory or simple speed. However, it seems more plausible that the lack of associations is the mere consequence of the fact that these tasks do not draw heavily on an intact visual input system. This is consistent with the notion put forward by the information degradation hypothesis, which assumes that the association between sensory and cognitive functioning is the result not of impaired cognitive performance but of difficulties in the sensory phase of perception, which may compromise performance on neuropsychological tests. Although the results of some authors (e.g. $\left.{ }^{10}\right)$ do not support this theory, those of others studies do. ${ }^{11,17}$

The sensory deprivation and resource allocation hypotheses were postulated to explain the direct causal relationship between sensory impairment and cognitive performance. In the present investigation, cataract surgery or hearing aid use did not affect (ameliorate) cognitive performance, suggesting that there is no long-term beneficial effect of improvement of sensory function on cognitive variables, but several methodological considerations must be taken into account. First, the group of participants that received a hearing prosthesis in the MAAS period was small, consisting of seven participants, which reduces the statistical power of the test. Second, with respect to the individuals that underwent cataract surgery, it is difficult to draw conclusions as to whether the operation was successful in terms of the objective gain in visual acuity. When the mean baseline visual acuity scores of this group were compared with their scores 6 years later, no overall improvement in the visual acuity measure was detected, although it may be 
Table 3. Association Between Sensory Functioning and Cognitive Performance After 6-Year Follow-Up Adjusted for Baseline Performance, Age, Education, and Sex

\begin{tabular}{|c|c|c|c|c|c|c|c|c|}
\hline & VVLT Total & VVLT r & SCWT $1+2$ & SCWT i & CST $A+B$ & CST i & Fluency & LDST \\
\hline Model Components & \multicolumn{8}{|c|}{$B$ value } \\
\hline \multicolumn{9}{|l|}{ Vision } \\
\hline \multicolumn{9}{|l|}{ Step 1} \\
\hline Age & $-0.25^{\dagger}$ & $-0.06^{\dagger}$ & $0.24^{\dagger}$ & $0.65^{\dagger}$ & $0.24^{\dagger}$ & $0.54^{\dagger}$ & $-0.12^{\dagger}$ & $-0.23^{\dagger}$ \\
\hline Education & $0.82^{\dagger}$ & $0.21^{\dagger}$ & -0.17 & -0.09 & $-0.41^{*}$ & $-1.35^{\dagger}$ & 0.14 & $0.39 *$ \\
\hline Sex & 1.06 & 0.14 & -0.99 & -2.57 & 0.14 & 1.40 & 0.35 & -0.59 \\
\hline$\Delta R^{2}$ & $0.22^{\dagger}$ & $0.16^{\dagger}$ & $0.18^{\dagger}$ & $0.12^{\dagger}$ & $0.25^{\dagger}$ & $0.13^{\dagger}$ & $0.13^{\dagger}$ & $0.34^{\dagger}$ \\
\hline \multicolumn{9}{|l|}{ Step 2} \\
\hline Baseline performance & $0.63^{\dagger}$ & $0.68^{\dagger}$ & $0.77^{\dagger}$ & $0.96^{\dagger}$ & $0.78^{\dagger}$ & $0.29^{\dagger}$ & $0.57^{\dagger}$ & $0.83^{\dagger}$ \\
\hline$\Delta R^{2}$ & $0.27^{\dagger}$ & $0.29^{\dagger}$ & $0.47^{\dagger}$ & $0.35^{\dagger}$ & $0.33^{\dagger}$ & $0.04^{\dagger}$ & $0.31^{\dagger}$ & $0.40^{\dagger}$ \\
\hline \multicolumn{9}{|l|}{ Step 3} \\
\hline Baseline vision & 1.46 & 0.60 & -2.24 & -2.27 & -0.96 & -3.12 & 1.40 & 1.18 \\
\hline$\Delta R^{2}$ & $<0.01$ & $<0.01$ & $<0.01$ & $<0.01$ & $<0.01$ & $<0.01$ & $<0.01$ & $<0.01$ \\
\hline \multicolumn{9}{|l|}{ Step 4} \\
\hline Change in vision & $5.47^{*}$ & $2.04^{\dagger}$ & $-5.25^{\dagger}$ & -6.17 & $-3.63^{*}$ & -8.50 & 0.87 & $4.74^{\dagger}$ \\
\hline$\Delta R^{2}$ & $0.01^{\dagger}$ & $0.01^{\dagger}$ & $0.01^{\dagger}$ & $<0.01$ & $0.01 *$ & 0.01 & $<0.01$ & $0.01^{\dagger}$ \\
\hline$R^{2}$ overall model & 0.50 & 0.46 & 0.65 & 0.48 & 0.59 & 0.17 & 0.44 & 0.74 \\
\hline \multicolumn{9}{|l|}{ Hearing } \\
\hline \multicolumn{9}{|l|}{ Step 1} \\
\hline Age & $-0.24^{\dagger}$ & $-0.07^{\dagger}$ & $0.29^{\dagger}$ & $0.87^{\dagger}$ & $0.25^{\dagger}$ & $0.43^{\dagger}$ & $-0.10^{\dagger}$ & $-0.20^{\dagger}$ \\
\hline Education & $0.78^{\dagger}$ & $0.18^{*}$ & -0.29 & -0.30 & $-0.49^{\dagger}$ & $-1.75^{\dagger}$ & 0.25 & $0.52^{\dagger}$ \\
\hline Sex & 0.50 & -0.04 & -0.71 & -2.49 & 0.01 & 2.41 & 0.16 & -0.91 \\
\hline$\Delta R^{2}$ & $0.22^{\dagger}$ & $0.15^{\dagger}$ & $0.19^{\dagger}$ & $0.14^{\dagger}$ & $0.27^{\dagger}$ & $0.13^{\dagger}$ & $0.13^{\dagger}$ & $0.37^{\dagger}$ \\
\hline \multicolumn{9}{|l|}{ Step 2} \\
\hline Baseline performance & $0.63^{\dagger}$ & $0.68^{\dagger}$ & $0.77^{\dagger}$ & $0.97^{\dagger}$ & $0.77^{\dagger}$ & $0.28^{\dagger}$ & $0.56^{\dagger}$ & $0.82^{\dagger}$ \\
\hline$\Delta R^{2}$ & $0.27^{\dagger}$ & $0.28^{\dagger}$ & $0.44^{\dagger}$ & $0.34^{\dagger}$ & $0.30^{\dagger}$ & $0.03^{\dagger}$ & $0.31^{\dagger}$ & $0.38^{\dagger}$ \\
\hline \multicolumn{9}{|l|}{ Step 3} \\
\hline Baseline hearing & -0.04 & -0.01 & $0.07^{*}$ & -0.21 & $<-0.01$ & -0.02 & -0.02 & $-0.06^{*}$ \\
\hline$\Delta R^{2}$ & $<0.01$ & $<0.01$ & $0.01 *$ & 0.01 & $<0.01$ & $<0.01$ & $<0.01$ & $<0.01^{*}$ \\
\hline \multicolumn{9}{|l|}{ Step 4} \\
\hline Change in hearing & $-0.24^{*}$ & $-0.07^{*}$ & 0.02 & 0.15 & 0.06 & 0.36 & -0.05 & -0.09 \\
\hline$\Delta R^{2}$ & $0.01^{\dagger}$ & $0.01 *$ & $<0.01$ & $<0.01$ & $<0.01$ & 0.01 & $<0.01$ & $<0.01$ \\
\hline$R^{2}$ overall model & 0.49 & 0.44 & 0.64 & 0.49 & 0.57 & 0.17 & 0.44 & 0.75 \\
\hline
\end{tabular}

${ }^{*} P<.05 ;{ }^{\dagger} P<.01 . V V L T=$ Visual Verbal Learning Test; SCWT $=$ Stroop Color Word Test; CST $=$ Concept Shifting Task; LDST $=$ Letter-Digit Substitution Task; $\Delta$ $R^{2}=$ change in coefficient of determination.

possible that this method was not sensitive enough to measure visual improvements that may be apparent in daily life, because visual acuity was measured binocularly. Thus, it is possible that other factors may have affected visual function in this group (e.g., a progression of cataract on one (or even both) eye, inadequate correction of nearby vision at the moment of testing, or even insufficient improvement of vision after surgery). Unfortunately, no information was available with regard to the status of the operation, whether one or two eye lenses were replaced, the optical correction was optimal, or additional treatment was required (e.g., laser therapy). Therefore, no firm conclusions can be drawn from the evaluation of cognitive effects of self-initiated intervention in this study.

A methodological concern about the current study involves the sample of participants used, which consisted of healthy individuals who volunteered to participate in the MAAS and had been doing so for more than 6 years. Inevitably, this selection of participants may have caused a bias in the results. Nevertheless, it has previously been shown that, although individuals who discontinue participation in MAAS are more likely to be older and have lower scores on cognitive tasks, this selection of dropouts did not substantially affect estimates of cognitive change. ${ }^{36}$ Moreover, a tendency toward a "restriction of range" in terms of cognitive variables due to dropout may result in less variability in performance measures. In this situation, the reported effect sizes may even reflect an underestimation of true associations.

In summary, although effect sizes were small, the findings support the notion of a strong connection between sensory acuity in auditory and visual domains and cognitive performance measures, from cross-sectional and longitudinal perspectives. No convincing evidence was found for a time lag between reduced sensory function and cognitive ability, which ultimately supports the hypothesis that this connection is primarily based on a reduced ability to process stimuli of neuropsychological test material efficiently. From a practical point of view, this implies that it is essential to screen individuals aged 55 and older in a clinical context 
for sensory functioning to avoid changes in visual or auditory acuity being interpreted as changes in cognitive performance. Adequate acknowledgment of vision and hearing impairments in older individuals therefore seems warranted. To draw conclusions about the causal relationship between sensory functioning and cognition in the future, it is suggested that controlled experiments to test the effect of interventions aimed at improving visual or auditory acuity be required.

\section{ACKNOWLEDGMENTS}

We thank Anita Hendriks, Carlein Karimoen, Mieke Kessel, Riet Landeweerd, Astrid Quist, and Nico Rozendaal for assistance in medical and neuropsychological testing and database construction.

\section{REFERENCES}

1. Schneider BA, Pichora-Fuller MK. Implications of perceptual deterioration for cognitive aging research. In: Craik FI, Salthouse TA, eds. The Handbook of Aging and Cognition. Mahwah, NJ: Erlbaum, 2000, pp 155-219.

2. Reuben DB, Mui S, Damesyn M et al. The prognostic value of sensory impairment in older persons. J Am Geriatr Soc 1999;47:930-935.

3. Horowitz A. Vision impairment and functional disability among nursing home residents. Gerontologist 1994;34:316-323.

4. Keller BK, Morton JL, Thomas VS et al. The effect of visual and hearing impairments on functional status. J Am Geriatr Soc 1999;47:1319-1325.

5. Lee P, Smith JP, Kington R. The relationship of self-rated vision and hearing to functional status and well-being among seniors 70 years and older. Am J Ophthalmol 1999;127:447-452.

6. Marsiske M, Klumb P, Baltes MM. Everyday activity patterns and sensory functioning in old age. Psychol Aging 1997;12:444-457.

7. Wallhagen MI, Strawbridge WJ, Shema SJ et al. Comparative impact of hearing and vision impairment on subsequent functioning. J Am Geriatr Soc 2001;49:1086-1092.

8. Anstey KJ, Lord SR, Williams P. Strength in the lower limbs, visual contrast sensitivity, and simple reaction time predict cognition in older women. Psychol Aging 1997;12:137-144.

9. Lindenberger U, Baltes PB. Sensory functioning and intelligence in old age: A strong connection. Psychol Aging 1994;9:339-355.

10. Lindenberger U, Scherer H, Baltes PB. The strong connection between sensory and cognitive performance in old age: Not due to sensory acuity reductions operating during cognitive assessment. Psychol Aging 2001;16:196-205.

11. van Boxtel MP, ten Tusscher MP, Metsemakers JF et al. Visual determinants of reduced performance on the Stroop color-word test in normal aging individuals. J Clin Exp Neuropsychol 2001;23:620-627.

12. Stankov L, Anstey K. Health and cognitive ageing: The emerging role of sensorimotor abilities. Aust J Ageing 1997;16:34-39.

13. Sekuler R, Blake R. Sensory underload. Psychol Today 1987;21:48-51.

14. Baltes PB, Lindenberger U. Emergence of a powerful connection between sensory and cognitive functions across the adult life span: A new window to the study of cognitive aging? Psychol Aging 1997;12:12-21.
15. Christensen H, Mackinnon AJ, Korten A et al. The 'common cause hypothesis' of cognitive aging: Evidence for not only a common factor but also specific associations of age with vision and grip strength in a cross-sectional analysis. Psychol Aging 2001;16:588-599.

16. Rabbitt P. Mild hearing loss can cause apparent memory failures which increase with age and reduce with IQ. Acta Otolaryngol Suppl 1990;476:167-175.

17. Van Boxtel MPJ, van Beijsterveldt T, Houx PJ et al. Mild hearing impairment can reduce verbal memory performance in a healthy adult population. J Clin Exp Neuropsychol 2000;22:147-154.

18. Sands LP, Meredith W. Effects of sensory and motor functioning on adult intellectual performance. J Gerontol 1989;44:56-58.

19. Anstey KJ, Luszcz MA, Sanchez L. Two-year decline in vision but not hearing is associated with memory decline in very old adults in a population-based sample. Gerontology 2001;47:289-293.

20. Jolles J, Houx PJ, van Boxtel MPJ et al., eds. Maastricht Aging Study. Determinants of Cognitive Aging. Maastricht: Neuropsychology Publishers, 1995.

21. Van Boxtel MPJ, Buntinx F, Houx PJ et al. The relation between morbidity and cognitive performance in a normal aging population. J Gerontol A Biol Sci Med Sci 1998;53A:M146-M154.

22. Metsemakers JFM, Höppener P, Knottnerus JA et al. Computerized health information in the Netherlands: A registration network of family practices. $\mathrm{Br}$ J Gen Pract 1992;42:102-106.

23. Bosma H, van Boxtel MP, Ponds RW et al. Mental work demands protect against cognitive impairment: MAAS prospective cohort study. Exp Aging Res 2003;29:33-45.

24. De Bie SE. Standaardvragen 1987: Voorstellen voor uniformering van vraagstellingen naar achtergrondkenmerken en interviews [Standard Questions: Proposal for Uniformization of Questions Regarding Background Variables and Interviews], 2nd Ed. Leiden: Leiden University Press, 1987.

25. Folstein MF, Folstein SE, McHugh PR. 'Mini-mental state'. A practical method for grading the cognitive state of patients for the clinician. J Psychiatr Res 1975;12:189-198.

26. Brand N, Jolles J. Learning and retrieval rate of words presented auditorily and visually. J Gen Psychol 1985;112:201-210.

27. Houx PJ, Jolles J, Vreeling FW. Stroop interference: Aging effects assessed with the Stroop color-word test. Exp Aging Res 1993;19:209-224.

28. Stroop JR. Studies of interference in serial verbal reactions. J Exp Psychol 1935;18:643-662.

29. Reitan RM. Validity of the Trail-Making Test as an indication of organic brain damage. Percept Mot Skills 1958;8:271-276.

30. Vink M, Jolles J. A new version of the Trail-Making Test as an information processing task. J Clin Neuropsychol 1985;7:162.

31. Luteijn F, van der Ploeg FAE. Handleiding Groninger Intelligentietest (GIT) [Manual Groningen Intelligence Test]. Lisse Swets and Zeitlinger, 1983.

32. Lezak MD. Neuropsychological Assessment, 3rd Ed. New York: Oxford University Press, 1995.

33. Smith A. The Symbol Digit Modalities Test: A neuropsychological test for economic screening of learning and other cerebral disorders. Learn Disord 1968;36:83-91.

34. Westheimer G. Visual Acuity. In: Moses RA, Hart WMJ, eds. Adler's Physiology of the Eye: Clinical Application. St. Louis: Mosby, 1987.

35. Davis A. Hearing in Adults. Nottingham: Whurr Publishers, 1995.

36. Van Beijsterveldt CE, van Boxtel MP, Bosma H et al. Predictors of attrition in a longitudinal cognitive aging study: The Maastricht Aging Study (MAAS). J Clin Epidemiol 2002;55:216-223. 